\title{
Die Praline
}

Alessia Schinardi

Korrespondenz:

Dr. med. Alessia Schinardi

Dufourstrasse 161

CH-8008 Zürich

Tel. 0443866600

aschinardi[at]zadz.ch
Es war einmal eine Praline, die alle für ihr Aussehen bewunderten und wegen ihres Aromas aussuchten, denn sie war nämlich eine der teuren Sorte. Sie hatte jedoch andere Pläne für ihr Leben, als auf dem Catwalk vor der berühmten Vitrine zu drehen, nein, sie wollte etwas anderes, Wirksames werden - eine Pille wollte sie werden!

«Eine Pille, was?», fragten die Schwestern derselben Schale im Chor.

«Eine Glückspille natürlich», antwortete sie. «Sagt nicht jeder, dass wir mehr Serotonin enthalten als ein Zoloft? Also, ich bestimmt.»

«Ja, und dann sagen auch alle, dass wir dick machen, dass wir vom Mund direkt auf den Hüften landen», verbesserte eine der älteren Schwestern. «So eine Pille würden nur Frauen schlucken.»

«Nein, auch die Schwulen», fügten die Schwesterchen im Chor hinzu.

«Und die Diabetiker?», entgegnete die ältere Praline. «Also basta! Ich kann nicht mehr in dieser Haut stecken, unsere Verpackung kostet mehr als unsere Herstellung. Ich schäme mich nicht, nackt wie eine Pille dazustehen.»

«Oh nein, nackt? Niemals!», schrien die jüngeren Pralinen empört. «In der Vitrine, wo alle die Herstellungsfehler sehen können!»

«Abgesehen davon, dass ich keinen Produktionsfehler habe, schäme ich mich meiner Rundungen

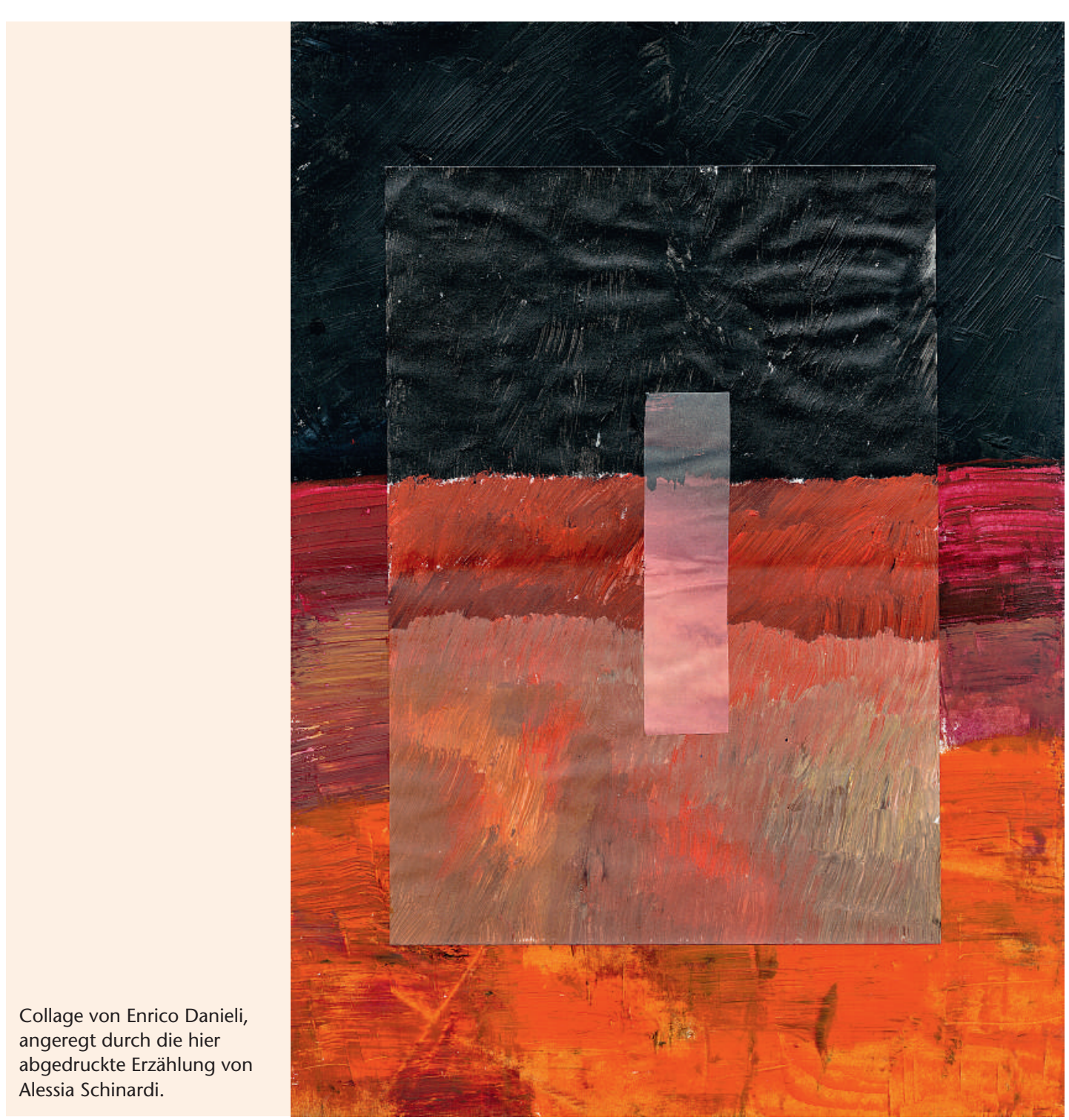


nicht. Ich lasse mich von euch nicht entmutigen. Ich warte hier auf meine Chance, und die wird bald kommen. Ihr seid vielleicht die zukünftigen Fettpölsterchen, ihr seid diejenigen, die man kiloweise, ohne nachzudenken, schluckt, bevor Krokodilstränen vergossen werden! Ich bin eine Glückspille. Macht Platz und seid still, meine Chance kommt gerade.»

«Wer? Die Ärztin da? Die, die schon mit Schamgefühlen in den Laden kommt, eine Menge von uns kauft, uns vorgaukelnd, wir seien als Geschenk zu verpacken?», murmelten die Pralinen.

«Nein, die andere, die Psychiaterin. Die, die auf alle Chemikalien allergisch ist. Wer sonst? Macht Platz in der Mitte, sie soll mich wählen!»

«Ich mach dir schon Platz», erwiderte die ältere Schwester, «aber ich sag dir jetzt schon, wir sehen uns bald im Magen.»

«Hier sind meine Pillen!», schrie die Psychiaterin und nahm sich gerade die ganze Schale Pralinen von dem Tischlein. «Heute muss ich dich einladen, liebe Paola, nach unserer Konversation werde ich mich für etwas zu entschuldigen haben.»

«Dann», sagte Paola, die beste Freundin und alte Studienkollegin, resigniert und griff nach der ersten Praline, direkt neben der Pille.

«Wie ich dir eben gesagt habe, liebe Paola ...».

«Moment mal, wenn du ¿Liebe Paola〉 sagst, brauche ich eine weitere Stärkung», sagte sie und griff schon zur zweiten Praline.

«Ich habe es dir gesagt», flüsterte eine der überlebenden Pralinen zu der Glückspraline.

«Eben, liebe Paola, wie ich dir schon mehrmals gesagt habe, ihr, die Hausärzte, seid die wahren Psychotherapeuten. Die leichten bis mittelschweren Depressionen, die Burnoutchen, die kleinen Erschöpfungen kommen gar nicht zu uns Psychiatern. Zum Glück, sage ich mal, sonst hätten wir keine Kapazität für die ernsthaft Kranken. Ich bin dir sehr dankbar für deinen Einsatz, niemand weiss genau, wie viele ihr täglich rettet, es steht hier, schwarz auf weiss im «Psychiater heute.»

«Danke für das Kompliment», sagte die Hausärztin, noch die x-te Praline kauend ... «Liebe Clara, das ist nichts Neues und auch nicht so schlimm, denn ich weiss: Es existiert keine Konkurrenz, sondern eine an- dere Schwelle, man erzählt immer noch nicht gern, dass man beim Psychiater war, aber bei uns trifft man sich gerne, wie in einem Café. Lass mich aber auch noch sagen, dass wir Hausärzte auch ohne die Heere von Depressiven genügend andere Patienten hätten.»

«Du vielleicht, liebe Paola, du hättest genügend Rheumatiker, die zu dir kommen würden, die Statistiken sagen jedoch klar, dass $40 \%$ der Patienten psychosomatischer Natur sind, diese sind Patienten, die selber auch keine Ahnung haben, dass sie depressiv sind ...»

Die Psychiaterin starrte gebannt die Praline-Pille an.

Nimm mich, nimm mich, betete diese.

Ich muss mir eine schnappen, dachte die Psychiaterin, bevor Paola alle frisst ...

Sie nahm die Pille und packte sie langsam aus ...

«Weisst du», fuhr die Psychiaterin fort, «dass diese schwarze Dame da», sie betrachtete nachdenklich die nackte Praline auf ihrer Handfläche, «mehr Serotonin enthält als die Antidepressiva, die im Handel sind?»

Ich bin bereit, wisperte die Glückspille.

Die Psychiaterin atmete tief ein und sagte: «Das ist keine Praline, das ist eine Glückspille, ich schwöre es dir.»

«Bei mir sind sie nicht so wirksam», erwiderte Paola, «wie viele habe ich schon geschluckt?»

«Also der «Psychiater heute» ist sich sehr klar darüber, dass eine von diesen, morgens früh nach dem Kaffee, wirksamer ist als all die Pseudoantidepressiva, die ihr verabreicht ... Ich werde eine Patenturkunde verlangen ...»

«Das behauptet der «Psychiater heute», sagst du», Paola gönnte sich noch eine Praline, «...also, der «sychiater heute» schreibt, dass eine von diesen da», und sie nahm noch eine ..., «reichen würde, um meine Patienten glücklich zu machen ...»

«Genau! Bei deinen leicht bis mittelschwer Depressiven ...», antwortete die Psychiaterin, die Glückspille anstierend.

«Diese Pillen würden sowieso nur bei Frauen - oder bei Frauen und Schwulen - Erfolg haben», sie schluckte eine weitere Praline und sagte: «und die Diabetiker?...»

Den Rest wisst ihr schon. 